\title{
Rural-urban differences on the rates and factors associated with early initiation of breastfeeding in Nigeria: further analysis of the Nigeria demographic and health survey, 2013
}

Emmanuel Olorunleke Adewuyi ${ }^{1,2}$, Yun Zhao ${ }^{3}$, Vishnu Khanal ${ }^{4^{*}}$, Asa Auta ${ }^{5}$ and Lydia Babatunde Bulndi ${ }^{6}$

\begin{abstract}
Background: This study investigates and compares the rates and factors associated with early initiation of breastfeeding (EIBF) within one hour of birth in rural and urban Nigeria.
\end{abstract}

Methods: Data from the 2013 Nigeria Demographic and Health Survey (NDHS) were analyzed. The rates of EIBF were reported using frequency tabulation. Associated factors were examined using Chi-Square test and further assessed on multivariable logistic regression analysis.

Results: The rates of ElBF were 30.8\% (95\% confidence interval [CI] 29.0, 32.6) and $41.9 \%(95 \% \mathrm{Cl} 39.6,44.3)$ in rural and urban residences, respectively $(p<0.001)$. The North-Central region had the highest EIBF rates both in rural $(43.5 \%)$ and urban (63.5\%) residences. Greater odds of EIBF in rural residence were significantly associated with higher birth order (Adjusted Odds Ratio [AOR] 1.29, 95\% Cl 1.10, 1.60), large birth size (AOR 1.33, 95\% Cl 1.10, 1.60), and health facility delivery (AOR 1.46, 95\% Cl 1.23, 1.72). Rural mothers in the rich wealth index, not working and whose husbands obtained at least a secondary school education had significantly higher odds of early initiation of breastfeeding. Regardless of residence, greater odds of EIBF were significantly associated with non-cesarean delivery (Rural AOR 3.50, 95\% Cl 1.84, 6.62; Urban AOR 2.48, 95\% Cl 1.60, 3.80) and living in North-Central (Rural AOR 1.84, 95\% Cl 1.34, 2.52; Urban AOR 4.40, 95\% Cl 3.15,6.15) region. Also, higher odds of EIBF were significantly associated with living in North-East (Rural AOR 1.48, 95\% Cl 1.05, 2.08; Urban AOR 3.50, 95\% Cl 2.55, 4.83), South-South (Rural AOR 1.51, $95 \% \mathrm{Cl} 1.11$, 2.10; Urban AOR 2.84, 95\% Cl 2.03, 3.97) and North-West (Urban residence only AOR $2.08,95 \% \mathrm{Cl} 1.54,2.80$ ) regions.

Conclusions: Rural-urban differences in the rates and factors associated with EIBF exist in Nigeria with rural residence having significantly lower rates. Intervention efforts which address the risk factors identified in this study may contribute to improved EIBF rates. Efforts need to prioritize rural mothers generally, (particularly, those in rural North-West region) as well as mothers in urban South-West region of Nigeria.

Keywords: Breastfeeding initiation, Determinants, Infants feeding, Mothers, Rural-urban Nigeria

* Correspondence: khanal.vishnu@gmail.com

${ }^{4}$ Nepal Development Society, Bharatpur, Chitwan, Nepal

Full list of author information is available at the end of the article

(c) The Author(s). 2017 Open Access This article is distributed under the terms of the Creative Commons Attribution 4.0 International License (http://creativecommons.org/licenses/by/4.0/), which permits unrestricted use, distribution, and reproduction in any medium, provided you give appropriate credit to the original author(s) and the source, provide a link to the Creative Commons license, and indicate if changes were made. The Creative Commons Public Domain Dedication waiver (http://creativecommons.org/publicdomain/zero/1.0/) applies to the data made available in this article, unless otherwise stated. 


\section{Background}

Early initiation of breastfeeding (EIBF) is the practice of introducing breast milk to newborns in which baby is placed skin-to-skin with the mother within the first hour of delivery, as recommended by the World Health Organization (WHO) [1]. Being the first and the most important step to optimal breastfeeding (early initiation, exclusive for the first six months and then complementary breastfeeding for the first two years of life), EIBF remains one effective means of promoting the health and survival status of infants and mothers [2]. Timely initiation of breastfeeding within the first hour of birth means neonates are introduced to colostrum ('first milk') which confers numerous benefits including active and passive immunity against a wide range of pathogenic diseases $[1,2]$. It also reduces postpartum bleeding in mothers, as well as protects against the leading causes of neonatal mortality such as respiratory tract infections (pneumonia, in particular), diarrhea, and neonatal sepsis [2-5]. Maternal-child bonding, longer duration and greater breastfeeding success are some of the beneficial effects of EIBF [6]. Moreover, a convincing body of evidence reveals that EIBF reduces neonatal mortality by approximately $22 \%$ in Ghana [3] and 19\% in Nepal [7]. Despite its numerous benefits and the WHO recommendation, the rate of breastfeeding initiation within the first hour of delivery is poor in many countries around the world [2].

In Nigeria, breastfeeding ('any breastfeeding') is universally practiced, however, the rate of EIBF is low and declining [8, 9]. Evidence from the national households surveys in Nigeria indicates that the rate of EIBF increased from $31.9 \%$ in 2003 to $38.4 \%$ in 2008 but decreased sharply to $33.2 \%$ in 2013 [9]. These rates are lower than those of similar developing countries like Ghana, the Gambia and Malawi at 46\%, 48\% and 56\%, respectively [10]. Studies have shown that a range of factors; socioeconomic, community, health, maternal and individual, may influence the rate of initiation of breastfeeding [11, 12]. In view of this premise, it is imperative to understand factors associated with EIBF in Nigeria. Regrettably, nationally representative studies on the rates and factors associated with breastfeeding initiation are limited in Nigeria.

Two recent and nationally representative studies have investigated the determinants of EIBF in Nigeria. Using the pooled (for the whole Nigerian population) 2013 Nigeria Demographic and Health Survey (NDHS), a study found a significant association between EIBF and place of delivery, mode of delivery, parity, birth size, maternal occupation, wealth index, and rural-urban residence [12]. Similarly, another study examined the trends and determinants of EIBF from 1990 to 2008 and reported maternal age at child's birth, mother's and father's education level, parity, residence, region, antenatal visit, mode and place of delivery as being significantly associated with EIBF [13].
However, all the studies to date only provided estimates based on the national average (overall Nigerian population) of EIBF and are limited, in that the withinpopulation variations such as the rural-urban differences were not assessed. In other words, they were based only on the pooled datasets and not disaggregated by rural-urban residence. Using pooled datasets or national average of estimates may mask the within population differences [14]. Thus, a gap in knowledge exists on how the rates and factors associated with EIBF differ between rural and urban residences in Nigeria. The present study aims to bridge this knowledge gap by disaggregating the most recent NDHS dataset along rural-urban residence thereby providing evidence-based, context-specific knowledge for addressing the challenge of low rates of EIBF in Nigeria.

The rural-urban stratification approach adopted in our study is in line with the growing consensus on using high quality disaggregated studies as an evidence-based method to bridge access/survival/equity gaps across socioeconomic and/or geographic divides $[15,16]$. Furthermore, the method agrees with the recent WHO's framework for monitoring progress towards Universal Health Coverage (UHC) which states: 'all measures should be disaggregated by socioeconomic and demographic strata' for a better assessment of equity in intervention coverage among other factors [14]. The approach may help capture context-specific factors which might not be possible with the use of 'one-size-fits-all' method of pooled datasets [16-18]. Given the beneficial effects of EIBF and the critical need for accelerated reduction in neonatal mortality, especially, in light of the ambitious targets for UHC (inscribed in the 2030 agenda for sustainable development) $[16,17]$, this study provides further evidence for target-specific interventions aimed at improving EIBF rates in Nigeria.

\section{Methods}

Dataset from the nationally representative NDHS, 2013, was analyzed in this study. NDHS is a public domain dataset available freely online (www.dhsprogram.com) with permission from ICF, International USA. A stratified three-stage cluster sampling design was used for sample collection in the survey and the design consisted of 904 clusters: 532 in rural residence and 372 in urban areas [9]. Interviewer-administered structured questionnaires were used for data collection and a total of 40,320 representative households were selected for the survey [9]. However, only $38,522(22,663$ in rural areas and 15,859 in urban areas), out of the 38,904 households occupied at field work time were successfully interviewed [9]. To reduce possible recall bias, data analyzed in this study were restricted to a total of 11,851 mothers who provided information on breastfeeding initiation on their last live 
childbirth within two years preceding the 2013 NDHS $[9,12]$. A comprehensive report on the setting, sampling design, questionnaires and sampling frame for the 2013 NDHS has previously been published [9].

\section{Study factors}

The outcome variable for this study was EIBF, defined as introducing breastfeeding to newborns within the first hour of delivery in line with the WHO recommendation [1]. Responses to the question on 'when child was put to breast' following delivery, in the 2013 NDHS [9], was re-categorized as 'within one hour' (early initiation, coded as ' 1 ') and 'beyond one hour' (late initiation, coded as ' 0 ') for use in logistic regression analyses. We selected independent variables based on the objective of this study and the review of previous studies [11-13] with consideration of the information available in the 2013 NDHS. The variables were broadly categorized into three groups; socioeconomic, biodemographic and health/support factors, in line with practice in previous studies [17-19].

Socioeconomic variables assessed in this study included mother's and father's education level (secondary/ higher, primary and none*), mother's occupation [re-categorized as not working (not working, households and domestic works), agriculture (paid and unpaid agricultural works) and paid works* (office, business, clerical, both skilled and unskilled manual) [11, 20], and wealth index. Wealth index, a proxy for household's socioeconomic status, was derived in the survey through the principal component analysis of available households' assets. Based on the similarities between the five categories captured in the $2013 \mathrm{NDSH}$, the variable was re-categorized into three in the present study as follows: rich = richer + richest, middle $=$ middle, and poor ${ }^{*}=$ poorer + poorest." [18].

Biodemographic variables assessed were birth type (single* and multiple), mother's age (re-categorized as: < $20^{*}, 20-34, \geq 35$ years), sex of child (male and female*), mother's religion (re-categorized as: Christianity, Islam* and Traditional/other) and birth size (re-categorized as follows large $=$ very large + larger than average, average $=$ average and small* ${ }^{*}=$ very small + smaller than average). 'Birth size' describes mothers' perception of the size of their babies at birth. The variable was used as a substitute for 'birthweight' given that information on birthweight was substantially missing in the 2013 NDHS, a common feature of most population-based surveys in developing countries like Nigeria $[9,21]$. There is evidence, however, that birth size estimates are usually closely related to the values of birthweight [22], thus, justifying the substitutionary use of the variable.

Other biodemographic factors included the region of residence (categorized according to the geo-political zones in Nigeria: North-Central, North-East, North-West, SouthEast, South-South and South-West*), mother's marital status (never married, formerly married and currently married $\left.^{*}\right)$ and birth order $\left(1^{*}, 2-3\right.$, and $\left.\geq 4\right)$. Health seeking/support factors, including antenatal attendance (none*, 1-3 and $\geq 4$ ), mode of delivery (cesarean section* and non-cesarean section vaginal) as well as the place of delivery (home* and health facility) were equally assessed in this study. These variables and their categorization compares well with those of previous studies in Nigeria and internationally $[11,12,17-19]$. (Note: " is the reference category used in analyses).

\section{Statistical analysis}

The rate (in \%) of EIBF alongside its 95\% CI were obtained against each aforementioned explanatory variables using frequency tabulation. Chi-Square test was performed and $p$ - values were reported to assess the unadjusted association between EIBF and the various explanatory variables by comparing the differences in the rate of EIBF between variable categories. To evaluate the adjusted relationship between EIBF and the explanatory variables, multivariable binary logistic regression analyses were carried out, accounting for the effects of all other explanatory variables included in the models.

To ensure that no important explanatory factors were missed, variables with $p \leq 0.20$ in the Chi-Square test were selected for inclusion in the initial multivariable regression model in line with practice in previous studies $[18,23]$. This cut-off point was chosen following a critical appraisal of evidence in the literature [24-26]. A backward elimination regression analysis was then performed to obtain the final parsimonious model, which only retained explanatory variables significantly associated with EIBF at $5 \%$ level $(p$ - value $<0.05)$. Adjusted odds ratios in the final parsimonious models together with their 95\% CI and $p$ - values were reported. To reduce possible statistical errors, analyses were double-checked, and all variables that satisfied inclusion criterion were included in our models. Also, our backward elimination modelling was tested by including potential confounders. All these analysis procedures were carried out separately for data disaggregated by rural-urban residence. All data management and analyses were performed using the Statistical Package for Social Sciences (SPSS), version 21. The sample weight and the multistage cluster design of the 2013 NDHS were accounted for using the Complex Sample Analysis method [27]. Where appropriate, the term 'residence' and 'areas' were used interchangeably in this study.

\section{Results}

Rates of EIBF in rural and urban residence

The demographic details of the sample, together with the percentage of mothers who fed breast milk to their newborns within the first hour of delivery are shown in 
Table 1. The rates of EIBF were 30.8\% (95\% CI 29.0, $32.6)$ and $41.9 \%(95 \%$ CI 39.6, 44.3) in rural and urban residence $(p<0.001)$, respectively (Table 1$)$. Regionally, the highest rates of EIBF occurred in the North-Central region both in urban $(63.5 \%, p<0.001)$ and rural $(43.5 \%$, $p<0.001)$ residences. On the other hand, the South-West $(28.3 \%, p<0.001)$ and the North-West $(21.6 \%, p<0.001)$ regions, had the lowest rates of EIBF in urban and rural residences, respectively (Fig. 1). Compared to their counterparts with no education (26.1\%), the rate of EIBF in rural residence was higher among mothers who had at least a secondary school education $(41.9 \%, p<0.001)$. Conversely, in urban residence, mothers with no education had a higher rate of EIBF (51.2\%) than their counterparts who had a secondary/higher education $(39.1 \%, p<0.001)$.

There was no statistically significant difference in the rates of EIBF between home (42.4\%) and health facility $(41.7 \%, p=0.761)$ delivery in urban residence. However, in rural areas, delivery in a health facility was significantly associated with higher rates of EIBF (42.4\%) than home delivery $(27.3 \%, p<0.001)$. Similarly, rich households in rural areas had significantly higher rate of EIBF $(44.2 \%)$ than their counterparts in poor households $(26.4 \%, p<0.001)$. In urban areas, there was no statistically significant difference in the rate of EIBF between the rich $(42.2 \%)$ and poor households $(37.5 \%, p=0.408)$.

Furthermore, rural mothers with at least four antenatal attendance had higher EIBF rates (36.5\%) than those who had no antenatal attendance $(25.0 \%, p<0.001)$. The reverse was the case in the urban residence where the rates of EIBF was significantly higher among mothers who had attended no or 1-3 times antenatal care compared to their counterparts with $\geq 4$ attendances $(p=0.027)$. Mothers who were delivered by cesarean section had lower rates of EIBF than their counterparts with non-cesarean delivery, regardless of living areas (Table 1). In rural areas, mothers professing Christianity had higher EIBF rates (40.0\%) than their Muslim counterparts $(26.7 \%, p<0.001)$. On the other hand, Muslim mothers in urban areas had higher EIBF rates (48.3\%) than Christian mothers (35.8\%, $p<0.001$ ).

\section{Factors associated with EIBF in rural and urban Nigeria}

Table 2 presents the results of the multivariable regression analyses. For rural residence, three socioeconomic factors, wealth index, mother's occupation and husband educational level, were significantly associated with EIBF. Similarly, three biodemographic (birth order, birth size and region of residence), as well as two health/support factors (place and mode of delivery), were found to be significantly associated with EIBF in the residence. Specifically, the odds of EIBF was 35\% higher among rural mothers in rich households compared to their poor counterparts (AOR 1.35, 95\% CI 1.06, 1.71), and 35\% greater among mothers who were not working or those engaged in households/domestic works relative to their counterparts in paid jobs (AOR 1.35, 95\% CI 1.15, 1.60). Mothers whose husband obtained at least a secondary school education had $28 \%$ increased odds of early initiation of breastfeeding (AOR 1.28, 95\% CI 1.07, 1.57). Similarly, rural mothers of birth order $\geq 4$ were $29 \%$ more likely to breastfeed within their first hour of delivery compared to those of birth order of one (AOR 1.29, $95 \%$ CI 1.10, 1.60). Further, the odds of EIBF was increased significantly among rural mothers living in the North-Central (AOR 1.84, 95\% CI 1.34, 2.52), NorthEast (AOR 1.48, 95\% CI 1.05, 2.08), and South-South (AOR 1.51, 95\% CI 1.11, 2.10) regions. Also, the odds of EIBF were $33 \%$ and $46 \%$ significantly higher among mothers who had delivered a large sized baby and in a health facility, respectively (Table 2). Lastly, in the rural residence, the odds of EIBF were 3.5-fold higher among mothers with a non-cesarean delivery compared to those with a cesarean section (AOR 3.50, 95\% CI 1.84, 6.62).

In urban residence, no socioeconomic factor was significantly associated with EIBF. However, one biodemographic factor (region of residence) and one health/support factor (mode of delivery) attained statistical significance (Table 2). Compared to the South-West region, urban mothers living in the North-Central (AOR 4.40, 95\% CI 3.15, 6.15), North-East (AOR 3.50, 95\% CI 2.55, 4.83), North-West (AOR 2.08, 95\% CI 1.54, 2.80), and South-South (AOR $2.84,95 \%$ CI 2.03, 3.97) regions had increased odds of EIBF. As the case in rural residence, urban mothers who had a non-cesarean delivery had 2.5-fold increased odds of EIBF compared to those who had undergone a cesarean section (AOR 2.48, 95\% CI 1.60, 3.80).

\section{Discussion}

We assessed the rates and factors associated with early breastfeeding initiation in rural and urban Nigeria. Previous Nigerian studies $[12,13]$ have focused on the whole nation using pooled datasets (for the whole population). We have gone a step further to focus on the rural and urban residences in the country by analyzing disaggregated datasets. Our findings indicate that the rates of timely initiation of breastfeeding and the associated factors differ between rural and urban residences in Nigeria. For instance, a study has investigated the determinants of EIBF for the overall Nigerian population using the pooled 2013 NDHS [12]. The factors reported to be associated with EIBF by these authors; place of delivery, mode of delivery, parity, birth size, maternal occupation, and wealth index were mainly relevant in rural residence when we disaggregated the data by rural-urban residence. This highlights the importance of data disaggregation method in identifying populationspecific factors for EIBF. 
Table 1 Sample characteristics and rates of early initiation of breastfeeding by rural and urban residence in Nigeria, NDHS 2013

\begin{tabular}{|c|c|c|c|c|c|c|}
\hline \multirow[t]{3}{*}{ Factors } & \multicolumn{3}{|c|}{ Rural residence } & \multicolumn{3}{|c|}{ Urban residence } \\
\hline & \multirow[t]{2}{*}{$\mathrm{N}^{\mathrm{a}}(\%)^{\mathrm{b}}$} & \multicolumn{2}{|l|}{ Rate of ElBF ${ }^{b}$} & \multirow[t]{2}{*}{$N^{a}(\%)^{b}$} & \multicolumn{2}{|l|}{ Rate of ElBF ${ }^{b}$} \\
\hline & & $\%(95 \% \mathrm{Cl})$ & $p$-value & & $\%(95 \% \mathrm{Cl})$ & $p$-value \\
\hline \multicolumn{7}{|l|}{ Socioeconomic factors } \\
\hline Mother's education level & & & $<0.001$ & & & $<0.001$ \\
\hline Secondary/higher & $1837(20.6)$ & $41.9(38.7,45.1)$ & & $2345(59.7)$ & $39.1(36.4,41.9)$ & \\
\hline Primary & $1514(17.2)$ & $34.5(31.5,37.6)$ & & $776(19.4)$ & $40.6(36.1,45.3)$ & \\
\hline None & $4592(62.2)$ & $26.1(23.9,28.5)$ & & $787(20.9)$ & $51.2(46.2,56.2)$ & \\
\hline Mother's Occupation & & & $<0.001$ & & & 0.011 \\
\hline Paid work & $4092(52.6)$ & $28.3(26.1,30.5)$ & & $2624(68.0)$ & $40.5(38.0,43.1)$ & \\
\hline Agriculture & $1140(13.6)$ & $37.5(33.2,41.9)$ & & $201(4.4)$ & $38.2(31.3,45.7)$ & \\
\hline Not working & $2657(33.8)$ & $32.3(29.5,35.1)$ & & $1059(27.6)$ & $46.1(42.1,50.1)$ & \\
\hline Father's education level & & & $<0.001$ & & & 0.009 \\
\hline Secondary/higher & $2540(30.3)$ & $39.8(37.3,42.4)$ & & $2536(66.8)$ & $41.4(38.6,44.2)$ & \\
\hline Primary & $1456(18.4)$ & $33.4(30.1,36.9)$ & & $674(17.8)$ & $39.0(34.2,44.0)$ & \\
\hline None & $3667(51.3)$ & $24.7(22.3,27.1)$ & & $558(15.4)$ & $50.4(44.2,56.6)$ & \\
\hline Wealth index & & & $<0.001$ & & & 0.408 \\
\hline Rich & $1303(14.3)$ & $44.2(40.2,48.2)$ & & $2808(73.4)$ & $42.2(39.6,44.9)$ & \\
\hline Middle & $1682(20.4)$ & $35.5(32.3,38.9)$ & & $686(16.2)$ & $43.5(37.4,49.8)$ & \\
\hline Poor & $4958(65.3)$ & $26.4(24.3,28.7)$ & & $414(10.4)$ & $37.5(31.0,44.5)$ & \\
\hline \multicolumn{7}{|l|}{ Biodemographic factors } \\
\hline Mother's marital status & & & 0.539 & & & 0.046 \\
\hline Never married & $203(2.1)$ & $27.3(20.7,35.0)$ & & $115(2.6)$ & $28.8(19.7,40.0)$ & \\
\hline Formerly married & 169 (1.9) & $34.0(25.1,44.1)$ & & $100(2.4)$ & $38.9(28.8,49.9)$ & \\
\hline Currently married & $7571(96.0)$ & $30.8(29.0,32.7)$ & & $3693(95.0)$ & $42.4(40.0,44.8)$ & \\
\hline Mother's age & & & 0.007 & & & 0.135 \\
\hline$\geq 35$ & $1654(20.2)$ & $31.3(28.3,34.5)$ & & $837(21.6)$ & $45.7(41.3,50.1)$ & \\
\hline 20-34 years & $5498(69.2)$ & $31.6(29.6,33.6)$ & & $2900(73.8)$ & $40.8(38.2,43.5)$ & \\
\hline$<20$ years & 791 (10.6) & $24.8(21.1,28.9)$ & & $171(4.6)$ & $42.5(33.8,51.7)$ & \\
\hline Mother's religion & & & $<0.001$ & & & $<0.001$ \\
\hline Christianity & $2783(30.1)$ & $40.0(37.0,43.0)$ & & $2057(50.3)$ & $35.8(32.9,38.9)$ & \\
\hline Traditional/other & $111(1.7)$ & $34.7(22.3,48.1)$ & & $45(1.0)$ & $40.9(25.4,58.5)$ & \\
\hline Islam & $5049(68.2)$ & $26.7(24.5,28.9)$ & & $1806(48.7)$ & $48.3(44.8,51.7)$ & \\
\hline Sex of child & & & 0.323 & & & 0.320 \\
\hline Male & $4042(50.3)$ & $31.3(29.2,33.5)$ & & $1979(50.0)$ & $41.0(38.0,44.0)$ & \\
\hline Female & $3901(49.7)$ & $30.3(28.3,32.4)$ & & $1929(50.0)$ & $42.9(39.9,46.0)$ & \\
\hline Birth order & & & 0.187 & & & 0.143 \\
\hline 1 & $1457(18.7)$ & $28.7(25.8,31.9)$ & & $874(22.4)$ & $38.3(34.1,42.7)$ & \\
\hline $2-3$ & $2387(30.3)$ & $32.1(29.5,34.8)$ & & 1420 (35.9) & $42.6(38.9,46.3)$ & \\
\hline$\geq 4$ & 4099 (51.0) & $30.8(28.7,33.0)$ & & $1614(41.7)$ & $43.4(40.2,46.6)$ & \\
\hline Birth size & & & $<0.001$ & & & 0.015 \\
\hline Large & $3403(43.4)$ & $33.7(31.3,36.2)$ & & $1801(45.2)$ & $45.1(41.6,48.6)$ & \\
\hline Average & 3164 (39.8) & $30.2(27.6,32.9)$ & & $1612(42.2)$ & $38.8(35.6,42.1)$ & \\
\hline Small & 1329 (16.8) & $24.9(22.0,28.1)$ & & $482(12.6)$ & $40.8(35.6,46.2)$ & \\
\hline
\end{tabular}


Table 1 Sample characteristics and rates of early initiation of breastfeeding by rural and urban residence in Nigeria, NDHS 2013 (Continued)

\begin{tabular}{|c|c|c|c|c|c|c|}
\hline \multirow[t]{3}{*}{ Factors } & \multicolumn{3}{|c|}{ Rural residence } & \multicolumn{3}{|c|}{ Urban residence } \\
\hline & \multirow[t]{2}{*}{$\overline{N^{a}(\%)^{b}}$} & \multicolumn{2}{|l|}{ Rate of ElBF ${ }^{\mathrm{b}}$} & \multirow[t]{2}{*}{$\mathrm{N}^{\mathrm{a}}(\%)^{\mathrm{b}}$} & \multicolumn{2}{|l|}{ Rate of $\mathrm{ElBF}^{\mathrm{b}}$} \\
\hline & & $\%(95 \% \mathrm{Cl})$ & $\overline{p \text {-value }}$ & & $\%(95 \% \mathrm{Cl})$ & $p$-value \\
\hline Birth type & & & 0.570 & & & 0.043 \\
\hline Multiple & $131(1.8)$ & $28.3(20.5,37.6)$ & & $66(1.6)$ & $27.3(16.4,41.8)$ & \\
\hline Single & 7812 (98.2) & $30.9(29.1,32.7)$ & & $3842(98.4)$ & $42.2(39.8,44.6)$ & \\
\hline Region of residence & & & $<0.001$ & & & $<0.001$ \\
\hline North-Central & $1207(16.2)$ & $43.5(39.2,47.9)$ & & $532(9.3)$ & $63.5(57.3,69.3)$ & \\
\hline North-East & $1911(19.9)$ & $33.6(29.9,37.6)$ & & $509(12.2)$ & $58.8(52.4,64.8)$ & \\
\hline North-West & $3001(44.2)$ & $21.6(19.0,24.4)$ & & $698(22.4)$ & $46.1(40.6,51.7)$ & \\
\hline South-East & $383(4.4)$ & $42.5(34.4,51.0)$ & & $69317.7)$ & $30.9(26.1,36.2)$ & \\
\hline South-South & $994(9.5)$ & $41.3(36.4,46.3)$ & & $437(9.3)$ & $52.2(46.0,58.3)$ & \\
\hline South-West & $447(5.8)$ & $29.7(24.6,35.4)$ & & $1039(29.1)$ & $28.3(24.6,32.2)$ & \\
\hline \multicolumn{7}{|c|}{ Health-seeking/support factors } \\
\hline Antenatal visit & & & $<0.001$ & & & \\
\hline$\geq 4$ & 3209 (39.3) & $36.5(34.0,39.0)$ & & $2934(77.3)$ & $40.1(37.6,42.8)$ & 0.027 \\
\hline $1-3$ & $1136(14.4)$ & $31.7(27.9,35.5)$ & & $437(12.0)$ & $48.0(42.3,53.7)$ & \\
\hline None & 3446 (46.3) & $25.0(22.5,27.7)$ & & $391(10.7)$ & $47.6(39.6,55.7)$ & \\
\hline Mode of delivery & & & 0.032 & & & $<0.001$ \\
\hline Non-CS & 7844 (98.9) & $30.9(29.1,32.8)$ & & 3664 (95.9) & $43.0(40.5,45.5)$ & \\
\hline CS & $87(1.1)$ & $18.5(10.7,29.9)$ & & $176(4.1)$ & $24.1(17.1,32.8)$ & \\
\hline Place of delivery & & & $<0.001$ & & & 0.761 \\
\hline Health facility & $1942(23.1)$ & $42.4(39.3,45.5)$ & & $2546(63.5)$ & $41.7(38.9,44.5)$ & \\
\hline Home & 5984 (76.9) & $27.3(25.4,29.3)$ & & 1355 (36.5) & $42.4(38.5,46.4)$ & \\
\hline
\end{tabular}

Significance at $5 \%$ level. ${ }^{a}$ unweighted count. ${ }^{b}$ weighted percentage, NDHS Nigeria demographic and health survey

The finding that urban residence had significantly higher EIBF rates than rural residence is not surprising, and, several factors may have contributed to such difference. First, cultural practices/beliefs such as discarding colostrum because it 'is dirty/rusty' may contribute to lower rates of EIBF and this would expectedly be prevalent in rural than urban residence in Nigeria [28]. Second, access to and utilization of healthcare facility may facilitate the practice of early breastfeeding initiation, and rural residents in Nigeria are disproportionately disadvantaged in these regards [29, 30]. In the present study, for instance, mothers in urban residence had nearly two-fold greater

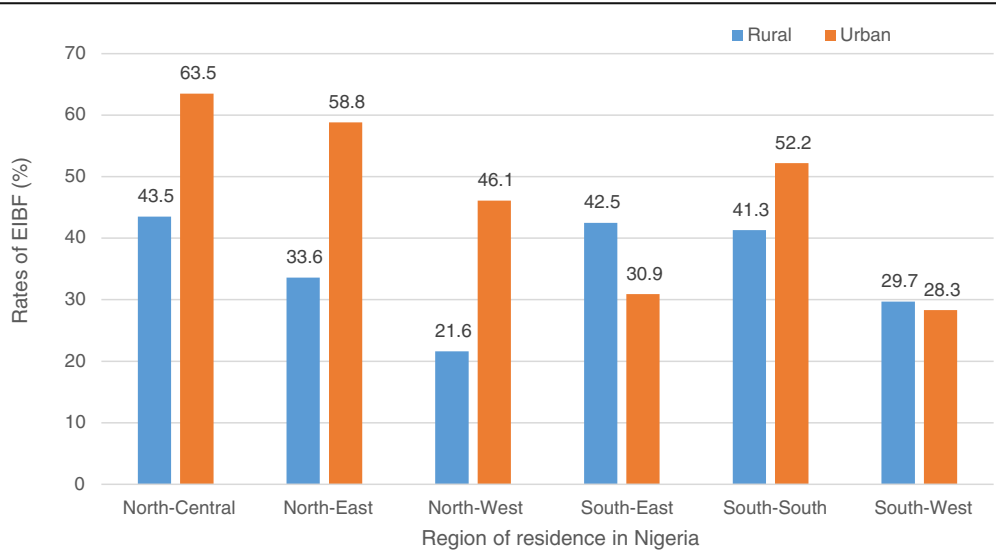

Fig. 1 Regional differences in the rates of Early Breastfeeding Initiation in Nigeria by rural-urban residence 
Table 2 Factors associated with early initiation of breastfeeding by rural-urban residence in Nigeria, NDHS 2013

\begin{tabular}{|c|c|c|c|c|c|c|}
\hline \multirow[t]{2}{*}{ Factors } & \multicolumn{3}{|c|}{ Rural Residence } & \multicolumn{3}{|c|}{ Urban Residence } \\
\hline & $\mathrm{AOR}$ & $95 \% \mathrm{Cl}$ & $p$-value & $A O R$ & $95 \% \mathrm{Cl}$ & $p$-value \\
\hline Wealth index & & & & - & - & - \\
\hline Rich & 1.35 & $1.06,1.71$ & 0.017 & - & - & - \\
\hline Average & 1.11 & $0.94,1.35$ & 0.316 & & & \\
\hline Poor & 1.00 & Reference & - & - & - & - \\
\hline Mother's occupation & & & & - & - & - \\
\hline Not working & 1.35 & $1.15,1.60$ & $<0.001$ & - & - & - \\
\hline Agriculture & 1.05 & $0.82,1.30$ & 0.706 & & & \\
\hline Paid work & 1.00 & Reference & - & - & - & - \\
\hline Husband's education level & & & & - & - & - \\
\hline Secondary/higher & 1.28 & $1.07,1.57$ & 0.010 & - & - & - \\
\hline Primary & 1.20 & $0.99,1.49$ & 0.068 & & & \\
\hline None & 1.00 & Reference & - & - & - & - \\
\hline Birth order & & & & - & - & - \\
\hline$\geq 4$ & 1.29 & $1.10,1.60$ & 0.003 & - & - & - \\
\hline $2-3$ & 1.14 & $0.94,1.40$ & 0.148 & & & \\
\hline 1 & 1.00 & Reference & - & - & - & - \\
\hline Birth size & & & & - & - & - \\
\hline Large & 1.33 & $1.10,1.60$ & 0.003 & & & \\
\hline Average & 1.22 & $1.02,1.46$ & 0.032 & - & - & - \\
\hline Small & 1.00 & Reference & - & - & - & - \\
\hline \multicolumn{7}{|l|}{ Region of residence } \\
\hline North-Central & 1.84 & $1.34,2.52$ & $<0.001$ & 4.40 & $3.15,6.15$ & $<0.001$ \\
\hline North-East & 1.48 & $1.05,2.08$ & 0.027 & 3.50 & $2.55,4.83$ & $<0.001$ \\
\hline North-West & 0.83 & $0.60,1.20$ & 0.340 & 2.08 & $1.54,2.80$ & $<0.001$ \\
\hline South-East & 1.34 & $0.84,2.13$ & 0.224 & 1.12 & $0.82,1.51$ & 0.490 \\
\hline South-South & 1.51 & $1.11,2.10$ & 0.010 & 2.84 & $2.03,3.97$ & $<0.001$ \\
\hline South-West & 1.00 & Reference & - & 1.00 & Reference & - \\
\hline Place of delivery & & & & - & - & - \\
\hline Health facility & 1.46 & $1.23,1.72$ & $<0.001$ & - & - & - \\
\hline Home & 1.00 & Reference & - & - & - & - \\
\hline \multicolumn{7}{|l|}{ Mode of delivery } \\
\hline Non-CS & 3.50 & $1.84,6.62$ & $<0.001$ & 2.48 & $1.60,3.80$ & $<0.001$ \\
\hline CS & 1.00 & Reference & - & 1.00 & Reference & - \\
\hline
\end{tabular}

Significance at 5\% level, CS Cesarean section, AOR Adjusted odds ratio, NDHS Nigeria Demographic and Health Survey

Factors adjusted for in rural residence: Mother's education level, mother's occupation, father's education level, wealth index, mother's age, mother's religion, birth order, birth size, region of residence, antenatal visit, mode of delivery and place of delivery

Factors adjusted for in urban residence: Mother's education level, mother's occupation, father's education level, marital status, mother's age, mother's religion, birth order, birth size, birth type, region of residence, antenatal visit and mode of delivery

antenatal attendance (of at least 4 times) and approximately three-fold higher prevalence of health facility delivery. Antenatal attendance and health facility delivery provide great avenues for information on the importance of EIBF. Hence urban women would more likely have acquired better breastfeeding knowledge, and, consequently, had higher EIBF rates than their counterparts in rural areas. Nevertheless, EIBF rates were generally low whether in rural or urban Nigeria (less than $50-89 \%$ deemed as good, and $90-100 \%$ considered as being very good by the WHO) [6]. This finding suggests the need for improved EIBF rates in both rural and urban Nigeria. However, given that rural residence had comparatively lower rates, greater attention is unarguably needed in the residence. 
Consistent with previous Nigerian studies (overall Nigerian population only) [12, 13], our study found cesarean delivery to be significantly associated with decreased odds of EIBF both in rural and urban residence. This finding may be linked with the rigor, stress and exhaustion that often go with cesarean deliveries including the effects/ complications of anesthesia [31]. The time-lapse between delivery, the repair of surgical incisions and recovery/ responsiveness following cesarean section may contribute to late breastfeeding initiation. Also, given that most women are averse to cesarean delivery in Nigeria [32] and the fact that the obstetric intervention is usually performed as the last option in life-threatening conditions [32], the occurrence of complications is likely and such may further contribute to the risk of late breastfeeding initiation. Mothers who had undergone cesarean section may be less likely to introduce their newborns (which may also have difficulty sucking) to breastfeeding within the recommended one hour after birth. However, it is noteworthy that with suitable guidance and appropriate support, early initiation of breastfeeding is possible even among mothers who had undergone cesarean section [31].

Our study reveals that the rates and the odds of EIBF were significantly higher in the North-Central region whether in rural or urban residence. On the other hand, the North-West and the South-West regions had the lowest rates of EIBF in rural and urban residences, respectively. Following multivariable analysis, the odds of EIBF was significantly higher in the North-Central, North-East, and South-South regions relative to the South-West both in rural and urban residence. These findings agree to some extent with those of previous studies for the overall $\mathrm{Ni}$ gerian population $[12,13]$. However, the reason for these regional variations in EIBF rates and odds is not clear. A likely explanation, nonetheless, would be the impact of sociocultural practices/beliefs. For instance, in a community in South-West region of the country, the acceptable breastfeeding norms were prelacteal feedings of water, herbal infusions and ritual fluids [28]. Consequently, newborns in the said community were normally introduced to water and complementary feeding almost immediately after delivery [28]. Similarly, a study in the North-West region reported that colostrum was considered unfit for consumption in neonates because it was 'dirty' and 'rusty' [33]. These and similar sociocultural practices/beliefs may have contributed to the differences in rates and the odds of EIBF observed in the present study.

Notably, the association between EIBF and the region of residence was generally stronger in urban compared to rural residence. For instance, while mothers in both rural and urban North-Central region had greater odds of EIBF, the odds were over two-fold higher for urban mothers. This finding is similarly true for mothers in the
North-East and the South-South regions indicating that urban mothers in the named regions had greater odds of initiating their newborns into breastfeeding within the recommended one hour after birth timeframe than their rural counterparts. The reason for this result may be linked with rural-urban disparities in breastfeeding knowledge, access to-/utilization of maternal cares services and socio-cultural practices in Nigeria [28-30]. Context-specific interventions are, therefore, needed to bridge these ruralurban differences in the country.

Wealth index attained statistical significance in the multivariable analysis, albeit in rural residence only. This finding is consistent with our Chi-Square test results where wealth index categories exhibited a strong and significant association with EIBF rates in rural residence. Contrariwise, wealth index categories showed only a negligible and nonsignificant difference in EIBF rates in urban residence suggesting that the rates of EIBF were similar among the rich, the middle class as well as the poor in urban Nigeria. The finding in urban areas clearly recommends breastfeeding as a simple, cost-effective intervention suitable for- and practicable by all irrespective of socioeconomic status (wealth index category). Conversely, in rural residence, both the rates and the odds of EIBF were significantly higher in wealthy compared to poor households. A previous study using the pooled 2013 NDHS has reported a similar result for the whole Nigerian population [12]. However, a rural-urban disaggregation (as carried out in our study) indicates that the result applies mainly to rural residence in Nigeria [12]. Thus, poor households in rural Nigeria would require greater priority for improved EIBF rates.

A critical review of the literature, however, reveals mixed results in respect of the association between EIBF and wealth index. For instance, a study conducted in Indonesia found that mothers classed in the rich wealth index had increased odds of late initiation of breastfeeding compared to those in poor wealth category [34]. Furthermore, wealthy mothers in Pacific, East Asia, Middle East, and North Africa regions have been reported to have greater chances of later breastfeeding initiation than their poor counterparts $[34,35]$. These mixed findings may be explained by factors ranging from differences in educational attainment, and thus the level of breastfeeding knowledge to the marketing of breast milk substitutes and the purchasing power of the rich or subsidy for the poor [36]. Experience, attitudes, nature of work and the belief of mothers may equally contribute in some ways to the observed results.

Similar to the results for wealth index, health facility delivery was associated with increased odds and higher rates of EIBF than home delivery, but in rural residence only. This result may be credited to the effectiveness of Baby Friendly Hospital Initiative in rural Nigeria and our 
finding compares well with those of studies (pooled/ national average only) in Nigeria [12], Nepal [11] and Indonesia [34]. However, the EIBF rate of $42.4 \%$ found in health facility for rural residence falls below the 90 $100 \%$ recommended by the WHO suggesting the need to step up this initiative for a greater improvement in breastfeeding initiation rates in the residence. Besides, with only $23.1 \%$ (as found in the present study), the prevalence of health facility delivery in rural Nigeria remains unacceptably low. Future interventions would need to take cognizance of these findings for a holistic program/intervention design. In urban Nigeria, the rates of EIBF were nearly same for both home and health facility deliveries, showing no statistical difference, hence the factor did not make a selection for multivariable modelling. These results coupled with those of wealth index support our earlier position that urban residents in Nigeria possibly had better knowledge on the benefits of EIBF, hence the likely support from health facility delivery and the effects of higher socioeconomic status did not confer any appreciable advantage. Intervention(s)/practice(s) which may be responsible for these findings in urban residence need(s) to be investigated and replicated in rural Nigeria.

Our finding reveals that mothers in rural residence whose husbands had at least a secondary school education were more likely to initiate their newborns into breastfeeding within one hour of birth. Consistently, studies have shown that husband's support is the most important influence on breastfeeding initiation and continuation decisions [37, 38]. Hence, it is logical to anticipate that husbands with at least a secondary school education would have better breastfeeding knowledge and, thus, are able to support their spouse/partners for early breastfeeding initiation decision.

Furthermore, in rural residence only, mothers who were not working or those who reported being engaged in domestic/household works had greater odds of EIBF compared to their counterparts engaged in paid employments (office, business, clerical, as well as both skilled and unskilled manual). A similar result has been reported for the overall Nepalese population [11], and two reasons may explain the current finding. First, mothers in paid jobs are more likely to have better access to financial resources and thus more susceptible to the practice of formula feeding which in turn may contribute to the late initiation of breastfeeding. Second, cesarean delivery is known to contribute to late breastfeeding initiation and mothers in paid jobs may opt for the mode of delivery, given their financial capability to afford it $[9,11]$. However, there have been mixed reports in respect of the association between mothers' occupation and EIBF. For example, a study in Bangladesh found no association [39] while a prospective study in the United States found that mothers in professional jobs had higher odds of early breastfeeding initiation [40]. Future studies would need to further investigate the relationship between maternal occupation and EIBF.

Our findings further indicate that in rural residence, babies perceived as being small in size at the time of delivery or belonging to the first birth order had decreased odds of EIBF. Small sized babies may require special care owing to premature delivery and immaturity, thus, chances of late breastfeeding initiation may be higher among them compared to their large-sized counterparts. In the same vein, studies have shown that both the intention to breastfeed and early breastfeeding initiation is associated with previous breastfeeding experience [41]. Hence, findings in respect of the association of EIBF with birth size and parity in rural Nigeria agree with the literature [12, 41]. In urban residence, birth order and birth size did not attain statistical significance following adjustment for other variables in the multivariable logistic regression analysis. The finding is not surprising for 'birth order' given the result of our Chi-Square test that showed no significant difference in the rates of EIBF for the variable. Interestingly, the position expressed here may not hold strictly true in rural residence as 'birth order' which lacked statistical significance in the Chi-Square test became significant in the multivariable analysis justifying the criterion set $(p \leq 0.20)$ for model building in our study. The finding for 'birth size' in urban areas may be due to the masking effect of the 'region of residence' and 'caesarean delivery' which were overwhelmingly significant in the residence.

\section{Strengths and limitations}

Our study presents a snapshot of the rates and factors associated with early breastfeeding initiation in rural and urban Nigeria. National representativeness, high response rate, application of complex sample statistics in all analyses (to adjust for sample weights and cluster design of the survey) and low missing data are some of the strengths of this study. Others include large sample size and the use of rural-urban data disaggregation method. Nevertheless, this study is limited in that the cross-sectional design of the survey does not allow the causal relationship to be estimated. Also, data were self-reported, collected retrospectively and so prone to social desirability and recall biases. However, restricting our study to data in the two years preceding the 2013 NDHS reduces the chances of recall bias. To the best of our knowledge, this is the first study to investigate rural-urban differences in EIBF rates and associated factors using nationally representative data in Nigeria.

\section{Conclusions}

This study reveals the rural-urban differences in the rates and factors associated with EIBF in Nigeria. Findings 
indicate that efforts are needed for improved EIBF rates both in rural and urban residences, although greater attention is evidently required in rural areas in the country. Whether in rural or urban residence, it is imperative to address late breastfeeding initiation associated with cesarean delivery using appropriate guidance and supports. Also, findings suggest the need to prioritize mothers in urban South-West as well as those in the rural NorthWest regions for context-specific interventions including addressing sociocultural practices that may negatively impact on EIBF.

In rural residence, our study recommends improved health facility delivery and nutritional support to address late breastfeeding initiation associated with small birth size. Breastfeeding initiation support for primiparous mothers, and increased breastfeeding awareness/support for mothers in poor households are equally required in rural Nigeria. A multi-dimensional/sectorial approach including media campaign using appropriate behavior change communication models, the long-term approach of acquiring secondary/higher education, community mobilization and comprehensive training for health workers are implementable interventions. These would need to give a special consideration for rural residence in Nigeria. However, more evidence is needed to explain the regional variations in the rates and odds of EIBF found in this study. Hence, we recommend that future studies further explore the regional differences in the rates and factors associated with EIBF in rural and urban Nigeria. Also, further studies are needed to investigate the causal relationship between the factors found to be associated with EIBF in rural and urban Nigeria.

\section{Abbreviations \\ AOR: Adjusted odds ratio; EIBF: Early initiation of breastfeeding; NDHS: Nigeria demographic and health survey; SPSS: Statistical package for social sciences; UHC: Universal Health Coverage; WHO: World Health Organization}

\section{Acknowledgements}

We gratefully appreciate ICF International, USA, for providing the NDHS data for this study. Also, authors thank Mary Ishaku Adewuyi for her generous support and encouragement in completing this work.

\section{Funding}

No funding was received for this study.

\section{Availability of data and materials}

The datasets analyzed during the current study are available in the Demographic and Health Survey repository, www.dhsprogram.com.

\section{Authors' contributions}

$E O A, Y Z, V K$ and $A A$ participated in the design of the study. EOA performed the analysis and prepared the manuscript. YZ, VK, AA and LBB provided data analysis advice and critical revision of the manuscript. All authors read and approved the final manuscript.

\section{Ethics approval and consent to participate}

Our study was based on a secondary analysis of a public domain data, hence, ethical clearance was not required. Permission to use the data was sought and obtained from ICF International, USA.
Consent for publication

Not applicable

\section{Competing interests}

The authors declare that they have no competing interests.

\section{Publisher's Note}

Springer Nature remains neutral with regard to jurisdictional claims in published maps and institutional affiliations.

\section{Author details}

${ }^{1}$ Statistical and Genomic Epidemiology Laboratory, Institute of Health and Biomedical Innovation, Queensland University of Technology, Brisbane, Australia. ${ }^{2}$ Federal Ministry of Defense, 2 Division Hospital, Adekunle Fajuyi Cantonment, Ibadan, Oyo State, Nigeria. ${ }^{3}$ Department of Epidemiology and Biostatistics, School of Public Health, Curtin University, Bentley Campus, Perth, Australia. ${ }^{4}$ Nepal Development Society, Bharatpur, Chitwan, Nepal. ${ }^{5}$ School of Pharmacy and Biomedical Sciences, University of Central Lancashire, Preston, UK. ${ }^{6}$ Mashiah Foundation Hospital, Jos, Plateau State, Nigeria.

Received: 16 June 2017 Accepted: 8 December 2017

Published online: 29 December 2017

\section{References}

1. World Health Organization. Indicators for assessing infant and young child feeding practices: part 1: definitions: conclusions of a consensus meeting held 6-8 November 2007 in Washington DC, USA. Geneva: WHO Press; 2008

2. Victora CG, Bahl R, Barros AJ, França GV, Horton S, Krasevec J, Murch S, Sankar MJ, Walker N, Rollins NC. Breastfeeding in the 21st century: epidemiology, mechanisms, and lifelong effect. Lancet. 2016;387:475-90.

3. Edmond KM, Zandoh C, Quigley MA, Amenga-Etego S, Owusu-Agyei S, Kirkwood BR. Delayed breastfeeding initiation increases risk of neonatal mortality. Pediatrics. 2006;117(3):e380-6.

4. Bahl R, Frost C, Kirkwood BR, Edmond K, Martines J, Bhandari N, Arthur P. Infant feeding patterns and risks of death and hospitalization in the first half of infancy: multicentre cohort study. Bull World Health Organ. 2005;83:418-26.

5. Debes AK, Kohli A, Walker N, Edmond K, Mullany LC. Time to initiation of breastfeeding and neonatal mortality and morbidity: a systematic review. BMC Public Health. 2013;13(3):S19.

6. Infant and young child feeding: a tool for assessing national practices, policies and programmes. http://apps.who.int/iris/bitstream/10665/42794/1/ 9241562544.pdf. Accessed May 09, 2017.

7. Mullany LC, Katz J, Li YM, Khatry SK, LeClerq SC, Darmstadt GL, Tielsch JM. Breast-feeding patterns, time to initiation, and mortality risk among newborns in southern Nepal. J Nutri. 2008;138:599-603.

8. Adewuyi EO, Adefemi K. Breastfeeding in Nigeria: a systematic review. Int J Community Med Public Health. 2016;3:385-96.

9. National Population Commission (NPC) [Nigeria] and ICF International: Nigeria Demographic and Health Survey 2013. In. Abuja, Nigeria and Rockville, Maryland, USA: NPC and ICF International.; 2014.

10. World Breastfeeding Trends Initiative: The state of breastfeeding in 33 countries 2010. http://www.worldbreastfeedingtrends.org. Accessed May 09, 2017.

11. Adhikari M, Khanal V, Karkee R, Gavidia T. Factors associated with early initiation of breastfeeding among Nepalese mothers: further analysis of Nepal demographic and health survey, 2011. Int Breastfeed J. 2014;9:21.

12. Berde AS, Yalcin SS. Determinants of early initiation of breastfeeding in Nigeria: a population-based study using the 2013 demograhic and health survey data. BMC Pregnancy Childbirth. 2016;16:32.

13. Babatunde Yahya W, Adebayo SB: Modelling the trend and determinants of breastfeeding initiation in Nigeria. Child Dev Res 2013;1:1-9: e530396.

14. World Health Organisation, World Bank Group: Monitoring progress towards universal health coverage at country and global levels: framework, measures and targets. http://www.who.int/healthinfo/universal_health_coverage/report/ 2014/en/. Accessed May 05, 2017.

15. Hosseinpoor AR, Bergen N, Koller T, Prasad A, Schlotheuber A, Valentine N, Lynch J, Vega J. Equity-oriented monitoring in the context of universal health coverage. PLoS Med. 2014;11(9):e1001727.

16. UNICEF: Committing to Child Survival: A Promise Renewed, Progress Report 2014. 2014. New York, USA: UNICEF; 2015. 
17. Adewuyi EO, Zhao Y. Determinants of neonatal mortality in rural and urban Nigeria: evidence from a population-based national survey. Pediatr Int. 2017;59:190-200.

18. Adewuyi EO, Zhao Y, Lamichhane R. Risk factors for infant mortality in rural and urban Nigeria: evidence from the national household survey. Scand J Public Health. 2017:45:543-54.

19. Adewuyi EO, Zhao Y, Auta A, Lamichhane R. Prevalence and factors associated with non-utilization of healthcare facility for childbirth in rural and urban Nigeria: analysis of a national population-based survey. Scand J Public Health. 2017:45:675-82.

20. Khanal V, Adhikari M, Karkee R, Gavidia T. Factors associated with the utilisation of postnatal care services among the mothers of Nepal: analysis of Nepal demographic and health survey 2011. BMC Womens Health. 2014;14:19.

21. Imdad A, Bhutta ZA. Nutritional management of the low birth weight/ preterm infant in community settings: a perspective from the developing world. J Pediatr. 2013;162:S107-14.

22. Titaley CR, Dibley MJ, Roberts CL, Hall J, Agho K. Iron and folic acid supplements and reduced early neonatal deaths in Indonesia. Bull World Health Organ. 2010;88:500-8.

23. Ezeh OK, Agho KE, Dibley MJ, Hall JJ, Page AN. Risk factors for postneonatal, infant, child and under-5 mortality in Nigeria: a pooled cross-sectional analysis. BMJ Open. 2015;5:e006779.

24. Sun G-W, Shook TL, Kay GL. Inappropriate use of bivariable analysis to screen risk factors for use in multivariable analysis. J Clin Epidemiol. 1996;49:907-16.

25. Lo SK, Li IT, Tsou TS, See L. Non-significant in univariate but significant in multivariate analysis: a discussion with examples. Changgeng Yi Xue Za Zhi. 1995;18:95-101.

26. Hosmer Jr DW, Lemeshow S, Sturdivant RX: Model-building strategies and methods for logistic regression. Applied Logistic Regression. New York, New York: John Wiley \& Sons, Inc. 2000:89-151.

27. West BT. Statistical and methodological issues in the analysis of complex sample survey data: practical guidance for trauma researchers. J Trauma Stress. 2008:21:440-7.

28. Davies-Adetugbo AA. Sociocultural factors and the promotion of exclusive breastfeeding in rural Yoruba communities of Osun state, Nigeria. Soc Sci Med. 1997;45:113-25.

29. Ijadunola KT, Fatusi AO, Orji EO, Adeyemi AB, Owolabi OO, Ojofeitimi EO, Omideyi AK, Adewuyi AA. Unavailability of essential obstetric care services in a local government area of south-west Nigeria. J Health Popul Nutr. 2007;25:94-100

30. Abegunde D, Kabo IA, Sambisa W, Akomolafe T, Orobaton N, Abdulkarim M, Sadauki H. Availability, utilization, and quality of emergency obstetric care services in Bauchi state, Nigeria. Int J Gynaecol Obstet. 2015;128:251-5

31. Pérez-Escamilla R, Maulén-Radovan I, Dewey KG. The association between cesarean delivery and breast-feeding outcomes among Mexican women. Am J Public Health. 1996;86:832-6.

32. Sunday-Adeoye I, Kalu CA. Pregnant Nigerian women's view of cesarean section. Niger J Clin Pract. 2011;14:276-9.

33. Oche M, Umar A, Ahmed H. Knowledge and practice of exclusive breastfeeding in Kware. Nigeria Afr Health Sci. 2011;11:518-23.

34. Titaley CR, Loh PC, Prasetyo S, Ariawan I, Shankar AH. Socio-economic factors and use of maternal health services are associated with delayed initiation and non-exclusive breastfeeding in Indonesia: secondary analysis of Indonesia demographic and health surveys 2002/2003 and 2007. Asia Pac J Clin Nutr. 2014;23:91-104.

35. Childinfo: monitoring the situation of women and children. http://www. childinfo.org/breastfeeding_status.htm. Accessed May 27, 2017.

36. Heck KE, Braveman P, Cubbin C, Chávez GF, Kiely JL. Socioeconomic status and breastfeeding initiation among California mothers. Public Health Rep. 2006;121:51-9.

37. Hunter T. Breastfeeding initiation and duration in first-time mothers: exploring the impact of father involvement in the early post-partum period. Health Promot Perspect. 2014;4:132-6.

38. Bar-Yam NB, Darby L. Fathers and breastfeeding: a review of the literature. J Hum Lact. 1997;13:45-50.

39. Haider R, Rasheed S, Sanghvi TG, Hassan N, Pachon H, Islam S, Jalal CS. Breastfeeding in infancy: identifying the program-relevant issues in Bangladesh. Int Breastfeed J. 2010;5:21.
40. Dagher RK, McGovern PM, Schold JD, Randall XJ. Determinants of breastfeeding initiation and cessation among employed mothers: a prospective cohort study. BMC Pregnancy Childbirth. 2016;16:194.

41. Lessen R, Crivelli-Kovach A. Prediction of initiation and duration of breastfeeding for neonates admitted to the neonatal intensive care unit. J Perinat Neonatal Nurs. 2007;21:256-66.

\section{Submit your next manuscript to BioMed Central and we will help you at every step:}

- We accept pre-submission inquiries

- Our selector tool helps you to find the most relevant journal

- We provide round the clock customer support

- Convenient online submission

- Thorough peer review

- Inclusion in PubMed and all major indexing services

- Maximum visibility for your research

Submit your manuscript at www.biomedcentral.com/submit 